\title{
Regulatory Experimentation in Energy: Three Pioneer Countries and Lessons for the Green Transition
}

\author{
Tim Schittekatte ${ }^{\mathrm{a}, \mathrm{c}, *}$, Leonardo Meeus ${ }^{\mathrm{a}, \mathrm{c}}$, Tooraj Jamasb ${ }^{\mathrm{b}}$, Manuel Llorca ${ }^{\mathrm{b}}$ \\ a Florence School of Regulation (FSR), Robert Schuman Centre for Advanced Studies, European University Institute, Italy \\ b Copenhagen School of Energy Infrastructure (CSEI), Department of Economics, Copenhagen Business School, Denmark \\ c Vlerick Energy Centre, Vlerick Business School, Belgium
}

\begin{abstract}
Regulation cannot always move as fast as innovation. Regulatory experiments enable real-life testing of new products, services or business models by allowing derogations from existing rules while maintaining the protection of energy consumers. The outcomes of these experiments inform future regulation. In this chapter, we discuss the experiences with regulatory experimentation in the energy sector of three pioneering countries: the Netherlands, Great Britain and Italy. We compare the implementations along six dimensions: eligible project promoters, scope of the derogations, length of the derogations, administration of the experiments, funding, and transparency. We also describe how the early approaches have evolved in these countries. Finally, we look ahead and discuss how learnings can be applied to enable experimentation at the European level involving technologies that are expected to become important to enable the green transition.
\end{abstract}

KEYWORDS: Innovation, Research and Development, Energy Regulation, Energy Retail, Green Deal JEL classification: L5, L9, O3, Q4, Q5

\section{INTRODUCTION}

The Green Transition, formalised in the EU as the Green Deal, relies on disruptive innovation, new technologies, and sustainable solutions to achieve the EU's decarbonisation objectives (European Commission, 2019). Regulation cannot focus solely on the cost-efficient use of existing infrastructure and investment in replacement and reinforcement; it also needs to consider innovation. The Council of European Energy Regulators (CEER) recognises that it is a challenge for National Energy Regulators (NRAs) to keep up with changes in the sector and to ensure that policy and regulation do not create unjustified barriers against innovation, while continuing to empower and protect consumers during the transition (CEER, 2019). In this chapter, we discuss regulatory experimentation, a new tool in the regulatory toolbox which allows for more adaptive regulation. The need for regulatory experimentation is often related to solutions which were not previously thought of or not necessary, related to new challenges in the energy system.

There is academic literature discussing regulatory experimentation, such as that by Bennear and Wiener (2019) and Fenwick et al. (2016). Without focussing on a specific sector, these authors explain that with new science, technology, and social conditions emerging there is interest in moving from static to adaptive regulation, i.e. in designing regulation to incorporate learning over time. Bennear and Wiener (2019) distinguish between unplanned adaptive (e.g. crisis response, ad hoc retrospective review) and planned adaptive (e.g. periodic review, adaptive licensing) regulation. Within planned adaptive regulation they further distinguish between discretionary and automatic mechanisms. Another relevant work is a paper by Zetzsche et al. (2017), which describes experiences with regulatory approaches to fostering innovation in the financial sector. It classifies regulatory approaches in several categories ranging from doing nothing, to cautious permissiveness (on a case-by-case basis, or through special charters), structured experimentalism and developing specific new regulatory frameworks. Finally, it introduces a new approach coined a 'smart regulation process'.

This chapter focuses on the approaches to regulatory experimentation in the energy sector in three pioneering European countries: Italy, the Netherlands, and Great Britain (GB). We cover the early approaches in these countries, discuss how they evolved over the years and provide learnings from the results to enable experimentation with new types of technologies that are expected to be vital to enable the green transition. Similar initiatives have also been recently launched in France ('bac á sable réglementaire') and Austria ('Energie.Frei.Raum') (CRE, 2020; FFG, 2020). Most of these approaches to regulatory experimentation closely resemble 'regulatory sandboxes', a form of structured experimentalism. The idea behind a sandbox had its origin in software engineering: a sandbox is an environment for running potentially unsafe 
code without the risk of infecting the entire system. Regulatory sandboxes have previously been introduced in other sectors such as banking and healthcare. Ringe and Ruof (2020) elaborate on the concept of regulatory sandboxes in great depth. There is very limited literature on regulatory experimentation specifically in the energy sector. Lo Schiavo et al. (2013) describe three case studies of innovative regulation in Italy and van der Waal, Das, \& van der Schoor (2020) analyse the Dutch experience. Broeckx et al. (2019) and ISGAN (2019) collect case studies from Australia, Austria, Germany, Italy, the Netherlands, Great Britain and the United States.

The chapter is organised as follows. First, we discuss how regulatory experimentation fits in the regulatory toolbox to foster innovation. Second, we compare three early approaches to regulatory experimentation in Italy, the Netherlands, and Great Britain. Third, we discuss how the approaches to regulatory experimentation in these three countries have evolved after the initial experiences. Fourth, we apply the lessons learned to the European Green Deal.

\section{REGULATORY TOOLS TO FOSTER INNOVATION}

Traditionally, the regulators' toolbox to foster innovation was limited. Tools differed depending on whether the regulation applied to regulated or market parties. In this section, we first describe how regulated network companies have been incentivised to invest in innovation. Second, we show how waivers are used to enable the business models of new market actors and activities. Third, we introduce regulatory experimentation and compare it with the more traditional regulatory tools.

First, to stimulate the adoption or facilitation of innovation by a regulated network company, regulators had to revise their regulatory frameworks. Traditionally, the primary objective of monopoly regulation was to cut costs. This was done in several countries by moving from cost-plus to incentive regulation, with Great Britain playing a pioneering role (e.g. see Jamasb and Pollitt (2007) and Rious and Rossetto (2018)). However, in order to cost-effectively integrate more and more renewables and fully leverage the new opportunities enabled by digitalisation, additional incentives for the uptake of innovation were needed. Examples of such regulatory tools are output-regulation, the remuneration of innovative network investments with a higher return and competition for innovation grants (Bauknecht, 2011; Jenkins \& Pérez-Arriaga, 2017; Meeus \& Saguan, 2011). This topic was already discussed in Jamasb et al. (2020).

Second, to stimulate new market players and activities, an important regulatory tool is waivers. Waivers are narrowly defined exemptions that are granted for strictly defined activities or types of actors. The exemption applies automatically to all concerned. It is explicitly granted following a regulatory decision and can be revisited when the innovation has sufficiently matured. Waivers can also be granted implicitly by regulators turning a blind eye to new activities or actors. An example is the waiver of balance responsibility for wind and solar generators. The European Commission reports that 12 of the 28 EU Member States did not include any form of financial obligation on wind and solar power produc- ers for balancing in 2013 (European Commission, 2013). Besides other regulated revenue schemes promoted by public authorities, such as those described by Glachant (2019), this waiver was another form of support. Without it, wind and solar power producers would have been exposed to greater risk, and this risk could have rendered their novel business models non-viable. These technologies have matured and Electricity Regulation (EU) $2019 / 943$ subsequently mandated that all market parties had to be balanced responsible, with only a few exceptions.

Third, regulatory experimentation is relatively new and not yet widely used by energy regulators. Regulatory experimentation can apply to both market and regulated parties independently of whether they are new or old players. We define regulatory experimentation as a temporary removal of regulatory barriers. This can be in the form of a derogation from a rule, but it can also mean assigning responsibility to players to conduct activities that they are normally not allowed to engage in. The regulator has an important role in the regulatory experiments but is not necessarily always the entity granting the derogations; it depends on the (national) approaches. An important difference between regulatory experimentation and waivers is that the experience gained from a regulatory experiment is essential to inform the revision of existing regulation or inspire new regulation. In other words, regulatory learning is a clear objective. Another difference is that regulators typically grant derogations on a case-by-case basis, based on a file submitted by the experimenter, while with waivers the derogation automatically applies to all parties that comply with certain criteria.

\section{THE EARLY APPROACHES TO REGULATORY EXPERIMENTATION IN ITALY, THE NETHERLANDS, AND GREAT BRITAIN}

In this section, we start by introducing the early approaches to regulatory experimentation in the three selected countries and describe the six dimensions used to compare them. Subsequently, we describe these national implementations using these dimensions and briefly discuss the choices that were made.

\subsection{INTRODUCTION OF EARLY APPROACHES AND THE SIX DIMENSIONS}

First, the Italian regulator ARERA is very active in promoting innovation in the energy sector and since 2010 has been launching several regulatory experiments to test new technologies, new services and new business models in the field. ${ }^{1}$ An overview can be found in ISGAN (2019). Lo Schiavo et al. (2013) describe experiences with several regulatory experiments in more depth, for example the earliest experiments with smart grids and public Electric Vehicle (EV) charging infrastructure. In this section, we focus on this latter experiment. A call for demonstration projects was launched in 2010. Five pilots out of a maximum of six, representing three different business models for EV charging facilities, were selected from ten applications in 2011. Finally, four projects were actually carried out (Lo Schiavo et al., 2017). We 
TABLE 1. SUMMARY OF THE THREE APPROACHES ALONG SIX DIMENSIONS

\begin{tabular}{|l|l|l|l|l|l|l|}
\hline & $\begin{array}{l}\text { Eligible project } \\
\text { promoters }\end{array}$ & Derogations & Length of derogations & Administration & Funding & Transparency \\
\hline $\begin{array}{l}\text { IT } \\
(2010-2015)\end{array}$ & $\begin{array}{l}\text { DSOs or third-party } \\
\text { EV charging station } \\
\text { operators }\end{array}$ & Targeted & 3-4 years & $\begin{array}{l}\text { Regulator, with external } \\
\text { experts helping in the } \\
\text { selection procedure }\end{array}$ & Yes & $\begin{array}{l}\text { 6-month reports and } \\
\text { final reports to the } \\
\text { regulator. Final public } \\
\text { report. }\end{array}$ \\
\hline $\begin{array}{l}\text { NL } \\
(2015-2018)\end{array}$ & $\begin{array}{l}\text { Initially communities } \\
\text { and homeowner asso- } \\
\text { ciations }\end{array}$ & Menu of options & Default: 10 years & $\begin{array}{l}\text { Ministry with advice } \\
\text { and monitoring from } \\
\text { the regulator }\end{array}$ & No & $\begin{array}{l}\text { 6-month or yearly meet- } \\
\text { ups of experiments. } \\
\text { Progress reports, not } \\
\text { public. }\end{array}$ \\
\hline $\begin{array}{l}\text { GB } \\
(2016-2017)\end{array}$ & $\begin{array}{l}\text { Communities and } \\
\text { companies }\end{array}$ & Open & Regulator & & \\
\hline & No & $\begin{array}{l}\text { Regular updates and } \\
\text { report at the end. Parts } \\
\text { of the final reports are } \\
\text { public. }\end{array}$ & & & & \\
\hline
\end{tabular}

focus on this experiment because both regulated (Distribution System Operators, DSOs) and non-regulated parties (EV charging service providers) took part, and because it had the aim of informing wider policy decisions.

Second, in the Netherlands, instead of waiting for a new gas and electricity act, the Dutch Ministry of Economic Affairs issued an executive order entitled 'Experiments in Decentralised Sustainable Electricity Production' (EDSEP). The objective of this executive order was to allow for experimentation with new energy services (Dutch Ministry of Economic Affairs, 2015). The Dutch regulator, ACM, had an advisory and monitoring role in the implementation of the executive order. ${ }^{3}$ The experiments started in 2015 and ended in 2018. 18 projects were initially awarded derogations and 15 of them are still active. No information has been found about the number of projects that applied, but a cap of 20 projects a year was set to limit the administrative burden. ${ }^{4}$

Third, the British energy regulator, Ofgem, has always been pushing the envelope in regulation at the world level. ${ }^{5}$ For example, Great Britain has a significant history of implementing incentive regulation in the period since 1990 (Jamasb and Pollitt, 2007). In December 2016, Ofgem's Innovation Link launched a regulatory sandbox initiative. It enables innovators to trial new products, services and business models without some of the usual rules applying. So far, Ofgem has run two application rounds ('windows') for the sandbox. These took place in 2017. Out of a total of 68 applications for the two calls, a total of seven sandboxes - three during the first window and four in the second were allowed to carry out trials (Ofgem, 2018b). ${ }^{6}$

We compare the approaches in these three countries along six dimensions. First, eligible project promoters. Eligible project promoters can be well-defined, or the call for project promoters can be open to all sorts of players. Second, derogations, namely whether the derogations are predefined by the regulator or whether it is the project promoter that takes the initiative and proposes them to the regulator. Third, the length of the derogations. Fourth, the administration of the regulatory experiments. The regulator could manage the whole process: the application procedure, approval, monitoring and/or evaluation of the experiment. It is also possible for a ministry or another institution to take the lead in some of these tasks. Fifth, the role of funding. A regulatory experiment could be tied to funding. Sixth and last, transparency of the experiments - whether the setup and results of the experiments were fully publicly disclosed or not.

\footnotetext{
${ }^{2}$ More information about the discussion concerning public EV charging facilities as a grey regulatory area can be found in Meeus and Schittekatte (2018).

${ }^{3}$ ACM stands for the Authority for Consumers and Markets. ACM regulates the Dutch telecom, transport, post, healthcare, and energy sectors.

${ }^{4}$ van der Waal et al. (2020) states that 18 projects were approved between 2015 and 2018. The Dutch Ministry of Economic Affairs and Climate states that currently 15 projects are active (RVO, 2020b).

5 Ofgem stands for the Office of Gas and Electricity Markets. It supports the Gas and Electricity Markets Authority and is the regulator for the electricity and downstream natural gas markets in Great Britain.

${ }^{6}$ At the time of writing, only two of the seven awarded sandboxes have commenced; a third has been delayed due to funding dependencies and may still commence.
} 


\subsection{DIMENSION 1: ELIGIBLE PROJECT PROMOTERS}

\begin{abstract}
National choices
In the Italian experiment, project promoters could apply to conduct one of three possible business models for an EV charging facility. These business models were distinct in terms of the operator (the DSO or a third party), the number of retailers competing at the recharging infrastructure level (mono or multi-vendor) and the degree of competition between charging stations allowed in a determined area (exclusive licence or not). More precisely, the three business models were the DSO as a multi-vendor, a third-party Charging Service Provider (CSP) with an exclusive licence for the geographical area (either multi-vendor or mono-vendor) and a third-party CSP in competition in the same area (typically mono-vendor). The selection criteria were detailed in regulatory decision ARG/elt 242/10 (AEEGSI, 2010). Please note that a third party applying for the experiment could be any kind of market player with an interest in EV charging service provision, from within (e.g. a retailer) or outside the electricity sector (e.g. a supermarket chain).
\end{abstract}

In the Netherlands, the project promoters eligible to apply for derogations were limited to homeowners' associations and energy communities. Two types of projects could be set up: small and large ones. A project grid limited to 500 users was considered a small project. In the case of a small project, the grid was owned by the project and had only one connection to the public grid. Larger experiments span up to 10,000 users and $5 \mathrm{MW}$ generation capacity. The project grids were usually operated in cooperation with the DSO and the DSO remained the owner of the grid. An example of the former is the Schoonschip project. Schoonschip is an association of the owners of 46 houseboats and one communal boat in the Buiksloterham quarter of Amsterdam. The homeowners' association acted as supplier, producer, and distributor of electricity. The administration of electricity use and supply was outsourced to a commercial electricity company which acted as Balance Responsible Party (BRP) and provided electricity when a shortage occurred, and purchased surplus electricity. An example of the latter is the Amersfoort Duurzame Stad project, which involved 820 households and a sports complex using a smart grid with blockchain technology to optimise the matching of local electricity production and demand.

In Great Britain, projects applying for a regulatory sandbox were assessed according to three general eligibility criteria instead of a narrow definition of eligible project promoters (Ofgem, 2017). First, the proposal had to be genuinely innovative, i.e., for a product or service not already being offered on the market or a new and sufficiently different business model being used to deliver the service or product. Second, the innovation had to have the potential to deliver consumer benefits and consumers had to be protected during the trial. Third, a regulatory barrier inhibited progress of the trial. All but one of the projects that were awarded a sandbox sought to maximise the benefits of locally produced (and sometimes stored) electricity for local consumers. The exception was a trial that implemented an innovative tariff supported by smart home technology to enable lower bills and warmer homes for customers with storage heaters. Some of the trials also explored the use of platforms to facilitate peer-topeer energy trading. The project promoters were very heterogeneous. For example, they varied from energy communities such as the Chase Solar Community to established international players such as BP and EDF and national suppliers such as OVO Energy. Only companies that were already licensed by Ofgem were allowed to be granted exemptions. If innovators were not licensed and were seeking exemptions, they needed to work with a licensed business (in most cases a supplier) (Ofgem, 2018d).

\section{Comparison and discussion}

For the Italian experiments, the project promoters could be DSOs or third parties. The third parties could choose between two business models. In the Dutch case, there were two sorts of eligible project promoters (energy communities and homeowners' associations) and the project could be small ( $\leq 500$ grid users) or large (> 500 and $\leq 10,000$ grid users). In the British case, all sorts of players could be project promoters, including regulated and market parties. Importantly, in all three country cases, we notice that most regulatory experimentation has been happening at the lower-voltage electricity grid, involving, for example, energy communities, retailers, DSOs and active consumers.

A difficulty related to eligibility is discrimination. In the case of market parties, there is a trade-off between allowing a derogation for one sort of actor or activity and risking the distortion of competition, and not allowing a derogation for that actor but risking that a potential welfare enhancing innovation does not materialise. The significance of the market distortion is a function of the exact derogation, the size of the actor being granted it, and its duration. There can also be discrimination in the case of regulated parties. For example, if in one area a DSO can implement an innovative network tariff, it can be argued that the grid users in that area are positively or negatively discriminated compared to the grid users under a default network tariff.

\subsection{DIMENSION 2: DEROGATIONS}

\section{National choices}

Lo Schiavo et al. (2017) and ISGAN (2019) state that a derogation from the ordinary tariff system was granted to the Italian EV charging pilots. More specifically, a special purely volumetric network tariff structure was introduced without fixed and capacity components. This was only applicable to network points of delivery dedicated to the public EV charging stations. In addition, by testing a model in which the DSO owned and operated the EV charging facility, the experiment allowed the DSO to undertake an activity that under normal circumstances was not allowed. To limit distortions with retail competition and cross-subsidisation issues, two special provisions were put in place for the DSO business model: the charging facility had to be 'multi-vendor,' i.e. with freedom of electricity supplier for each transaction, and there was accounting unbundling between the DSO business and the EV charging facility. ${ }^{7}$

\footnotetext{
7 After the transposition of European Directive 2014/94/UE (AFID Directive) into Italian law in 2016, DSOs were no longer allowed to invest in and operate recharging points. This activity can only be carried out by independent service providers within a competition frame (recitals 29-30 of Directive 2014/94/UE).
} 
In the Netherlands, the articles of the 2008 Electricity Act from which projects could be exempted were predefined in the EDSEP decree - a sort of 'menu' approach. ${ }^{8}$ The predefined exemptions related to the right to own and operate the grid, grid tariff discounts, DSO metering, obligations, and exemptions from supplier licences, certain specific rules regarding the transparency and liquidity of the energy market and obligations related to invoicing and data management. Broeckx et al. (2019) describe that the first eight projects approved requested all the possible relevant derogations without exception. van der Waal et al. (2020) explain in more detail the derogations that were requested in four selected projects.

In contrast with the Dutch approach under the EDSEP, in Great Britain the articles from which derogations could be requested were not predefined. With support from Ofgem, the applicant proposed the specific derogation(s) - more à la carte.' After a co-creating process between the innovator and Ofgem to obtain viable trial arrangements, Ofgem issued 'sandbox letters' to each innovator (Ofgem, 2018a). These letters set out its understanding of the proposed trial, how it expected the trial to operate within the regulatory framework, and the protections required for consumers participating in the trial. It must be noted that Ofgem, the government and a number of other industry bodies oversee different parts of the market and regulatory arrangements. Therefore, only derogations from rules under Ofgem's responsibility could be given. These are mostly related to licences. Examples are derogations from tariff requirements and communication rules between suppliers and customers. The derogations for each project are briefly described in Ofgem (2018a, 2018c). It is important to add that besides potentially granting derogations, all innovators could also rely on the regulator for bespoke guidance (about how regulation applied to their undertaking) and comfort (about Ofgem's approach to compliance and enforcement) for the period of their trial.

\section{Comparison and discussion}

In the Italian case, the derogations were targeted. In the Dutch case, a list of articles from which derogations could be granted was predefined. In the British case, derogations were not predefined and open for the innovators to propose.

An important consideration to be made when deciding about the scope of derogations and the process to grant them is regulatory effort versus tailored support. Allowing each experiment to have tailored derogations can give the innovators more room for creativity, but significantly increases regulatory effort as well as discrimination risks. Moreover, the scope of the derogations can be limited by laws and regulations which are not under the responsibility of the regulator but, for example, under the responsibility of the ministry or industry bodies. Importantly, derogations at the national level need to comply with European legislation.

\subsection{DIMENSION 3: LENGTH OF THE DEROGATIONS}

\author{
National choices \\ In the Italian case, the derogations lasted for three to four years. In the \\ Netherlands, the default duration of the derogation was ten years, but \\ extensions were possible. In Great Britain, derogations were granted for a \\ period of two years from the moment they were issued.
}

\section{Comparison and discussion}

The lengths of the derogations vary widely between two years in GB to ten years in the Netherlands. Italy lies in the middle.

A short duration of the derogation limits the potential market distortion caused by the experiment. In addition, a short duration can allow for quick learning and potential adaptation of the regulation. A long duration can give security to the innovators. Often, an innovator has to invest a significant amount of upfront capital and needs guarantees that their project will be able to run for at least several years.

\subsection{DIMENSION 4: ADMINISTRATION}

\section{National choices}

The Italian regulator was in charge of the administration of the experiment. Lo Schiavo et al. (2017) state that external experts from Ricerca sul Sistema Energetico (RSE), a research institute, provided help in the selection procedure. The selection criteria were identified by the regulator and the selection report is publicly available. As for administration of the cost coverage granted to selected pilots (see also Dimension 5), the ancillary body of the Authority for regulatory accounts (Cassa conguaglio del settore elettrico) was directly in charge, following mandates or ARERA.

In the Netherlands, the Ministry of Economic Affairs and Climate Change proposed the law regulating the possible derogations for the experiments. Initiatives that were willing to make use of the EDSEP needed to apply to the Dutch Enterprising Agency (in Dutch: Rijksdienst voor Ondernemend Nederland, RVO). RVO is an executive organisation of the Ministry of Economic Affairs and Climate. Finally, the regulator had an advisory and monitoring role.

In Great Britain, the regulator was in charge of the administration of the regulatory sandboxes. Regulatory sandboxes are part of Ofgem's Innovation Link, a 'one stop shop' offering support on energy regulation to businesses looking to launch new products, services or business models.

${ }^{8}$ Article 2 of the EDSEP lists the articles of the Electricity Act of 2008 from which project promoters can request a derogation (Dutch Ministry of Economic Affairs, 2015). 


\section{Comparison and discussion}

In the case of Italy and Great Britain, the experiments were completely the responsibility of the regulator. In the case of the Netherlands, the ministry and the Dutch Enterprising Agency had important roles, with the regulator having more of a supporting function.

A difficulty created by involving several institutions is coordination between them. van der Waal et al. (2020) show that in the Dutch experiments this was a very significant issue, as there were many actors involved in the process (the ministry, RVO, the regulator, the local authority, and the grid operator, among others). For example, after an experimenter informed and convinced the civil-servants in one unit, the experimenters met with resistance from the executive staff and had to re-explain their plans. van der Waal et al. (2020) argue that this issue could be solved by designating an intermediary to serve as a bridge between national and regional actors and provide regulatory and financial advice. An advantage of including other institutions in the setup of experiments is the possibility of allowing experimentation with legislation which is beyond the responsibility of the regulator but governed by the additional institutions involved.

\subsection{DIMENSION 5: FUNDING}

\section{National choices}

ISGAN (2019) states that the investment in charging facilities in the Italian experiment amounted to around EUR 2 million, which was covered through grants funded via tariffs. ${ }^{9}$ Moreover, Lo Schiavo et al. (2013) state that the financial contribution was awarded per charging point per year.

In the Dutch and British cases, no direct funding was coupled with the regulatory experiments. However, the projects could apply for other subsidies such as national or European funds.

\section{Comparison and discussion}

In the Italian case, the experiments were partly funded. No funding was coupled with the experiments in the Dutch and British cases.

Providing funding can attract more experimenters and might increase the possibility of success. On the other hand, public spending can increase network tariffs and might increase the distortion of competition. Nevertheless, if no funding is awarded, it is important that experiments are provided with guidance on how to secure national or European funding if they are eligible. However, being selected for a regulatory experiment does not imply an endorsement by the regulator and should not lead to positive discrimination when applying for external funding.

\subsection{DIMENSION 6: TRANSPARENCY}

\section{National choices}

In the Italian case, transparency was one of the key pillars. The regulator asked the project promoters to produce a detailed report every six months containing relevant information about the number of charging events, recharged energy, and the duration and occupation time of the charging points. A final report also had to be issued at the end of the whole demonstration project. Representatives of the Italian regulator and researchers from RSE also published a paper detailing the outcomes of the experiment and a synthesis of the final reports can be found online (Lo Schiavo et al., 2017; RSE, 2017).

In the Dutch case, to share learning experiences, RVO, the Dutch Enterprising Agency, organised meet-ups once or twice a year for the experiments, together with the national platform for community energy. Periodic progress reports also had to be filed by the experimenters. van der Waal et al. (2020) consider it unlikely that the experiences with the experiments will be influential in the revision of the energy law because no specific national representation of the experimenters exists and because the experimenters were not asked for their input during the consultation on the draft of the follow-up executive order. On the EDSEP website, only short descriptions of the projects and blog posts can be found (RVO, 2020a).

Finally, Ofgem required the innovators to maintain a risk management plan and provide regular updates during the trial. At the end of each trial, the innovators also had to produce a report on what had been learnt (Ofgem, 2018a). The report had to indicate what information could be anonymised, published, and used to inform policy development and what information was commercially confidential and should be protected. Brief case studies of several projects that were assisted by the Innovation Link Programme can be found on the regulator's website (Ofgem, 2020b). In addition, a summary of insights into how the regulatory sandbox approach itself can be improved were published (Ofgem, 2018b). These insights informed the way regulatory sandboxes evolved.

\section{Comparison and discussion}

Transparency is important in all three country cases. The emphasis on transparency was strongest in the Italian case. The regulator emphasised that not only the regulator should benefit but also other market and regulated parties should have the ability to profit and learn from the experiments. In the British and Dutch cases, the emphasis was put on regulatory learning and all the information on the experiments is not necessarily publicly available.

It is clear that regulators should obtain a full overview of the results of experiments in order to enable regulatory learning. However, there is discussion about whether all information regarding experiments should be made public. On the one hand, other regulated and market parties can benefit from the experiences. On the other hand, innovators might resist full disclosure of the experiment to protect their business ideas from competitors and so refrain from engaging in experiments.

\footnotetext{
9 Besides the cost for the retailing of the energy, EV users charging at selected charging points paid a "global" tariff that was set by the regulator. The global tariff included network charges and system levies, but not the cost of the charging infrastructure. The charging infrastructure was subsidized through grants funded by the overall tariff.
} 


\section{THE EVOLUTION OF REGULATORY EXPERIMENTATION IN ITALY, THE NETHERLANDS AND GREAT BRITAIN}

In all three countries, these first experiences with regulatory experimentation were considered positive and the initiatives quickly expanded. In this section, we first discuss how the approaches to regulatory experimentation evolved in the three countries. Afterwards, we briefly discuss whether the approaches are converging or diverging.

\subsection{ITALY: FROM REGULATORY PILOTS TO PILOT REGULATION (2017)}

The experiments conducted by the Italian regulator can be divided into two types. Three experiments of the 'first type,' often referred to as regulatory pilots, were concluded and are well-documented: the experiment involving different public EV charging infrastructure operators which was discussed in the previous section, an experiment involving smart grid demos set up by the DSO and an experiment in energy storage deployment by the Transmission System Operator (TSO) (Coppo et al., 2015; Lo Schiavo \& Benini, 2018; Lo Schiavo et al., 2017). All three experiments ran between 2010 at the earliest and 2017 at the latest. Recently, a consultation on a fourth regulatory pilot has been launched to test innovative practices in gas networks (39/2020/R/gas) (ARERA, 2020a). From 2017 onwards, experiments of a 'second type' were also launched. The difference between the two types is that in experiments of the second type, derogations are directly granted to all relevant actors complying with certain criteria ('system level'), while for those of the first type, the derogations are only granted to the actors that are successful in the application procedure ('local level'). Experiments of the second type are named 'pilot regulations', as the regulator is directly experimenting with the regulation itself.

Two pilot regulation experiments are being carried out. One is about the open protocol for interoperable in-home devices connected to new smart meters, and the other is about aggregators participating in the balancing market. We briefly introduce the latter experiment. It commenced with the Italian regulator issuing its Decision 300/2017/R/ eel as part of a review to comply with the Electricity Balancing Guideline (EB GL). As Galliani and Pasquadibisceglie (2018) show, the key concept of the experiment is that aggregators of small production and consumption units, 'virtual dispatchable units' (Unità Virtuale Abilitata, UVA, in Italian), are derogated from certain regulations to allow them to provide balancing power. Previously, these 'non-traditional resources' were excluded from participating in the balancing market. To identify the most promising solutions for the future, Terna, the Italian TSO, tests different solutions in terms of settling activated resources, fees in the case of non-delivery, and settling imbalances. At the time of writing, five calls for virtual dispatchable units to participate in the balancing market, differing in the types of technologies allowed, have taken place (ISGAN, 2019). ${ }^{10}$ The expected outcome of the whole initiative is that it will inform a review of the regulatory framework for the balancing market, enlarging the participation of distributed energy resources, either individually or through aggregation. ARERA publishes yearly the results of the pilot regulation within its yearly Report on renewables integration (e.g. see ARERA, 2020b).

\subsection{THE NETHERLANDS: FOLLOW- UP OF THE EDSEP (2020)}

At the time of writing, no formal evaluation of the first experiences with regulatory sandboxes has yet been published by the Dutch Ministry. However, lessons learnt from the EDSEP experiences have been used to draft a follow-up executive order.

It is foreseen that the new order will expand the size and scope of eligible projects, and also enable predefined exemptions under the Gas Act (RVO, 2020b). In addition, project promoters other than homeowners' associations and energy communities are allowed to apply for derogations, for example DSOs and energy suppliers. Examples of activities that fall within the scope of the new decree are running a local flexibility market and new business models for aggregators. It is proposed to keep the default ten-year duration of the exemption, with the possibility of an extension.

\subsection{GREAT BRITAIN: THE OFGEM REGULATORY SANDBOX 2.0 (2020)}

In the case of Great Britain, Ofgem published six insights after running the two calls for regulatory sandboxes (Ofgem, 2018b). Interestingly, the rather low number of sandboxes awarded (seven) compared to the total number of applications (68) is not due to innovators asking for unreasonable derogations. ${ }^{11}$ Instead, in most cases it was found that the proposed businesses could go ahead without needing a sandbox. What many innovators really needed was regulatory advice rather than a sandbox.

This learning informed a reform of the sandbox approach itself. In July 2020, Ofgem (2020a) published 'Energy Regulation Sandbox: Guidance for Innovators,' in which it explains in detail the working of the updated sandbox approach. Importantly, as in the Netherlands, Ofgem is consulting to expand the scope of the sandbox by adding two codes that can potentially be derogated from: the Balancing and Settlement Code (BSC) and the Distribution Connection Code (DCUSA). In this way, Ofgem will also work closely with the respective industry code administrators, Elexon and Electralink. Additionally, the Retail Energy Code (REC) will also build in sandbox flexibility. Finally, Ofgem is also consulting on extending the number of rules in the supplier licence which it can provide relief from. With the new sandbox approach, the tools available (bespoke guidance, comfort, confirmations, and derogations) can be more easily tailored to innovators wanting to undertake trials or wanting to enter the market. Another important change is that, unlike the original sandbox, innovators will be able to access the service when they need it rather than

\footnotetext{
${ }^{10}$ Marchisio et al. (2019) report that with almost $830 \mathrm{MW}$ of capacity qualified from virtual dispatchable units by the beginning of 2019 , the trial, despite its limits, may be considered a success.

11 Ofgem adds that there were 3 or 4 sandbox requests for formal derogations from current network charging rules. While Ofgem could technically provide derogations, they did not think it was appropriate to award derogations in areas subject to major policy reforms.
} 
only during strictly defined windows. Lastly, the trials will continue to be time limited but market entry sandboxes can receive enduring support. What is meant with enduring support is that the innovator receives a confirmation that its innovation is permissible. This confirmation applies for as long as regulation continues to allow for it. To address concerns about market distortions, the bilateral confirmation to an innovator will be accompanied with an anonymised public notification.

\subsection{CONVERGENCE OR DIVERGENCE?}

In terms of project promoters eligible to be subjects of regulatory experimentation, we notice that the first approaches focussed mainly on projects in the lower-voltage electricity grid involving energy communities, retailers, DSOs, active consumers and others. In all three country cases we see that the range of relevant or eligible project promoters widened as the scope of regulations that could be experimented with expanded. More specifically, in the Italian and Dutch cases, experiments related to gas were added to the scope of regulatory experimentation. In the British case, Ofgem (2020a) states that the vast majority of the 350 engagements in the three and a half years since Innovation Link was established relate to developments in electricity markets. However, this does not mean that innovators operating in gas markets cannot also seek support.

In terms of implementation of experiments, we see that the Dutch and British approaches are converging somewhat. In the Netherlands, the new approach is less restrictive regarding eligible project promoters and the number of articles from which derogations can be requested is increasing. In Great Britain, institutions other than the regulator are involved to allow for a wider range of derogations. However, a big difference remains concerning the duration of the derogations. The Italian pilot regulations are different to the Dutch and British regulatory sandboxes. The main difference is that the pilot regulations directly apply to all concerned whilst an application must be approved to be granted a Dutch and British regulatory sandbox. ${ }^{12}$ In addition, in the British, and to a lesser extent the Dutch, approach the innovators suggest the derogations. In this sense the experiments are innovator-led, while with pilot regulation the experiments are instead more regulator-led. Pilot regulation tends to mitigate issues with discrimination and distortion of competition, while regulatory sandboxes allow for more creativity from innovators. Both approaches demand high regulatory effort and expertise. Importantly, the two approaches do not exclude each other but could be used for different purposes.

\section{REGULATORY EXPERIMENTATION IN THE CONTEXT OF THE GREEN TRANSITIONN}

First, we discuss some technologies that may become more relevant in the context of the green transition and link the discussion with relevant EU legislation. Second, we discuss the case for regulatory experimentation at the EU level.

\subsection{TECHNOLOGIES AND EU LEGISLATION}

As previously discussed in this chapter, the first approaches to regulatory experimentation focussed mainly on projects in the lower-voltage electricity grid. These approaches evolved and the range of regulations which can be experimented with has expanded. Importantly, the gas sector will also be engaged more and more. However, the focus remains on the lower voltage/pressure levels. There is a good reason for this: the scope of these experiments lies within domains covered by EU directives (such as retail licences and distribution network tariffs). EU directives often allow for bottom-up national experimentation with regard to obligations for new actors or rules for new activities as long as certain principles are respected (i.e. the 'directions' set in the European legal texts).

However, innovation is also needed at higher voltage/pressure levels. For example, 'EU Strategy for Energy System Integration' clearly states that Power-to-X technologies will be crucial to integrate energy infrastructure (European Commission, 2020b). An example of a power-to-X technology is an electrolyser using electricity to split water into hydrogen and oxygen. There is even a separate work stream outlining the EU hydrogen strategy (European Commission, 2020a). Power-to-x technologies are also expected to become nominated as a Project of Common Interest (PCI) under the revised Trans-European Networks for Energy (TEN-E) Regulation. As Schittekatte et al. (2020) discuss, technologies enabling sector integration can be a (sometimes complementary) alternative to cross-border integration to allow for cost-efficient integration of renewables in the electricity grid. In this sense, the related technologies fall under EU regulations. At the national level, EU regulations cannot be deviated from. In other words, EU regulations define strict boundaries to national experimentation. The only possible way to deviate from EU regulations is when an exemption procedure is included in a regulation. A first example is merchant interconnectors. In this case, the exemption procedure allows market parties to conduct a by-default regulated activity. A second example is the ownership of storage. Conversely, this exemption procedure allows regulated parties to conduct a by-default market activity.

First, merchant interconnectors. By default, electricity interconnectors between two countries are regulated projects undertaken by national TSOs. As Kessel et al. (2011), de Hauteclocque and Rious (2011) and Cuomo and Glachant (2012) show, merchant projects have been exceptionally allowed as alternatives in the case that no TSOs are willing to construct a certain interconnector. Depending on the risks involved, national and European authorities can grant full or partial derogations, for example from rules related to congestion revenue, which are to be defined on a case-by-case basis. ${ }^{13}$ This exemption procedure leads to private capital being invested in interconnectors which are deemed important for the completion of the internal market, and allows third parties with different risk-return profiles to TSOs to test innovative technologies. To date, only seven exempted projects have been carried out in the EU (Gautier, 2020). ${ }^{14}$ The actors behind these projects are different in nature. Examples are BritNed, which is a joint venture of two TSOs, and ElecLink, a wholly-owned subsidiary of Getlink, the company that owns the Channel Tunnel concessionaire Eurotunnel.

\footnotetext{
12 An important difference between pilot regulation and waivers is that with pilot regulation the idea is not to simply return to the 'status-quo regulation' when the business model of the players or activity subject to the derogation/waiver has become viable. Instead, the objective is to adapt regulation on the basis of the results of the experiment.

13 Article 7 of Regulation (EC) 1228/2003 on cross-border exchanges organises the exemption process and similar rules exist in the Third Energy Package (Article 17 of Regulation (EC) 714/2009). In particular, exemptions from regulated third-party access (TPA) and the use of the congestion rent collected are relevant for merchant projects.
} 
Second, ownership of storage by system operators. ${ }^{15}$ According to Directive (EU) 2019/944, in principle, transmission or distribution system operators are not allowed to own, develop, manage or operate energy storage facilities. However, NRAs can grant derogation from this rule. This is possible if three conditions are (simultaneously) met (Arts. 36(2) and 54(2) of the Directive). ${ }^{16}$ First, market participants do not express an interest in owning, developing, managing or operating an energy storage facility. Second, the energy storage facility in question is necessary to fulfil obligations under the Electricity Directive to ensure system safety, efficiency and reliability. And third, the energy storage facility is not used to sell electricity to the market. Importantly, at regular intervals or at least every five years, the regulator must perform a public consultation on the existing energy storage facilities in order to assess the potential availability and interest of other parties in investing in such facilities. This exemption procedure is indeed a way to test different storage business models. However, other than a derogation from the unbundling rules for a system operator when certain conditions are met, which might be a barrier against deployment, no other potential barriers against innovation are lifted.

\subsection{THE CASE FOR REGULATORY EXPERIMENTATION AT THE EU LEVEL}

In their 'Bridge beyond 2025 Conclusions Paper,' ACER and CEER (2019) note that while several Member States are doing regulatory experimentation, no equivalent provision at the EU level exists. They state that this could limit the effectiveness of national action where EU rules are unintentionally getting in the way, and therefore propose the provision of an 'EU umbrella for the sandbox approach'. They also state that resulting lessons should be shared between NRAs to avoid the need to replicate pilots in each Member State and to accelerate decisions on whether regulation or legislation needs to be adapted.

However, ACER and CEER (2019) do not discuss the practical implementation of regulatory experimentation at EU-level. Inspiration can be drawn from the national case studies discussed in this chapter. A difference being that the involvement of an EU actor seems crucial. In this regard, ACER may be the right party if enough resources are provided. ${ }^{17}$ A first option could be to allow NRAs with approval from ACER or ACER itself to set up regulatory pilots or pilot regulations which deviate from EU regulation, as in the Italian case study. Binding EU principles or even guidelines on how to set up such experiments would be required. A second option could be to predefine which articles in EU regulations could be deviated from. This would mean extending the importance of exemption procedures beyond unbundling rules and is a similar approach to that in the Dutch case study. ACER, in coordination with the relevant NRAs, could be the body to approve these exemptions. Lastly, an EU-wide regulatory sandbox as in the British case could be set up and administered by ACER in coordination with the relevant NRAs. This seems to be the most ambitious option and would demand significant regulatory effort.

\section{CONCLUSION AND IMPLICATIONS FOR THE GREEN TRANSITION}

We have found that the early approaches to regulatory experimentation differ significantly in Italy, the Netherlands and Great Britain. At one end of the spectrum, the Italian regulator truly designed regulatory pilots with well-defined business models and targeted derogations, while at the other end, the British regulator left it open to all sorts of project promoters to design their own experiments. The approach in the Netherlands lays in the middle with a predefined 'menu of derogations' from which project promoters could choose. We have also discussed the main trade-offs to be made when implementing a regulatory experiment for six design dimensions.

Looking at how the approaches in these three countries are evolving, we have also found that the implementation of 'regulatory sandboxes 2.0 ' in Great Britain and the Netherlands seems to be converging, while the approach in Italy has evolved from designing regulatory pilots to pilot regulations. We notice that even though the scope of regulatory experiments is expanding (e.g. also covering gas legislation), most experimentation is happening at the lower voltage/pressure level. However, in order for the green transition to succeed, innovation with regard to technologies at the transmission level will also be needed. Examples are Power-to-X technologies enabling sector integration.

Currently, the only experiences with deviations from EU regulations have been exemption procedures. More is needed. We believe that when setting up an 'EU umbrella for the sandbox approach' as ACER and CEER (2019) propose, lessons can be learned from the national case studies discussed in this chapter. Starting with transposing the regulatory pilots as in the Italian approach or the menu of derogations as in the Dutch approach to the EU level might be the most realistic strategy in the shortterm. If experiences are positive, the step to EU-wide pilot regulations as in the Italian case or, ultimately, EU-wide sandboxes as in the British case can be taken. These different approaches can also complement each other. One approach might fit better for a certain context, as is also illustrated in the case studies. Finally, when thinking about regulatory experimentation at the EU level, involvement of an EU actor seems crucial. In this regard, ACER could be the right party under the condition that enough resources are provided to administer the regulatory experiments.

\section{ACKNOWLEDGEMENTS}

The authors are grateful to the participants at the online consultation and round table organised by FSR and CSEI on 30 April 2020. We are grateful for input from the panellists Neil Barnes (Ofgem), Luca Lo Schiavo (ARERA), Henriette Nesheim (EC), Luuk Spee (ACM) and the participants in the debate. We also acknowledge the useful and thorough comments by Kevin Baillie, Dierk Bauknecht, Klaus Kubeczko, Grace McLoughlin, Susanne Nies and Christoph von dem Bussche. The usual disclaimer applies.

\footnotetext{
${ }^{14}$ For an analysis of more case studies, see, for example, Coxe and Meeus (2010). Joskow (2019) presents an overview of the experience with merchant transmission lines in the US.

15 Art. 2(59) of Directive (EU) 2019/944 states that in the electricity system 'energy storage' means deferring the final use of electricity to a moment later than when it was generated, or the conversion of electrical energy into a form of energy which can be stored, the storing of such energy, and the subsequent reconversion of such energy into electrical energy or use as another energy carrier. Power-to-x falls under the category of energy storage, as Olczak and Piebalgs (2018) point out.

16 The same procedure is in place for recharging points (Art. 33(3)).
} 


\section{REFERENCES}

ACER, \& CEER (2019). The Bridge Beyond 2025. Conclusions Paper. 19 November 2019. AEEGSI (2010). Deliberazione ARG/elt 242/10. Disposizioni Speciali per l'erogazione Dei Servizi Di Trasmissione, Distribuzione e Misure e Del Servizio Di Dispacciamento Ai Fini Della Sperimentazione Dei Sistemi in Bassa Tensione Di Ricarica Pubblica Dei Veicoli Elettrici.

ARERA (2020a). Reti di trasporto e distribuzione del gas naturale: progetti pilota di ottimizzazione della gestione e utilizzi innovativi. Linee di intervento. https://www.arera. it/it/docs/20/039-20.htm (accessed: 18 December 2020).

ARERA (2020b). Stato di utilizzo e di integrazione degli impianti di produzione alimentati dalle fonti rinnovabili e di generazione distribuita. Anno 2019. Relazione 321/2020/I/ EFR

Bauknecht, D. (2011). Incentive Regulation and Network Innovations. Working Paper, EUI RSCAS, 2011/02, Loyola de Palacio Programme on Energy Policy.

Bennear, L. S., \& Wiener, J. B. (2019). Adaptive Regulation: Instrument Choice for Policy Learning over Time. DRAFT Working Paper -- Revised 12 February 2019

Broeckx, S., Ramos, A., Hadush, S. Y., \& Meeus, L. (2019). The future of DSOs. Our take on energy communities and regulatory sandboxes. Vlerick Business School-Energy White Paper.

CEER (2019). CEER Consultation on Dynamic Regulation to Enable Digitalisation of the Energy System: Conclusions Paper. Ref: C19-DSG-09-03. 10 October 2019.

Coppo, M., Pelacchi, P., Pilo, F., Pisano, G., Soma, G. G., \& Turri, R. (2015). The Italian smart grid pilot projects: Selection and assessment of the test beds for the regulation of smart electricity distribution. Electric Power Systems Research, 120, 136-149.

Coxe, R., \& Meeus, L. (2010). Survey of non-traditional transmission development. IEEE PES General Meeting, PES 2010, 1-6. https://doi.org/10.1109/PES.2010.5589749

CRE (2020). Guide du candidat au dispositif d'éxpérimentation reglementaire. Dernière Mise à Jour : 10 Juin 2020.

Cuomo, M., \& Glachant, J.-M. (2012). EU Electricity Interconnector Policy: Shedding Some Light on the European Commission's Approach to Exemptions. FSR Policy Brief, (2012/06).

de Hauteclocque, A., \& Rious, V. (2011). Reconsidering the European regulation of merchant transmission investment in light of the third energy package: The role of dominant generators. Energy Policy, 39(11), 7068-7077. https://doi.org/10.1016/j. enpol.2011.08.012

Dutch Ministry of Economic Affairs. (2015). Besluit van 28 februari 2015, houdende het bij wege van experiment afwijken van de Elektriciteitswet 1998 voor decentrale opwekking van duurzame elektriciteit (Besluit experimenten decentrale duurzame elektriciteitsopwekking). Staatsblad 2015, 99.

European Commission (2013). European Commission guidance for the design of renewables support schemes. Commission Staff Working Document. Brussels, 5.11.2013. SWD(2013) 439 Final.

European Commission (2019). The European Green Deal. Commission to the Communication from the European Parliament, the European Council, the Council, the European Economic and Social Committee and the Committee of the Regions- the European Green Deal. COM(2019) 640 Final. Published on 11.12.2019.

European Commission (2020a). A hydrogen strategy for a climate-neutral Europe. Communication from the Commission to the European Parliament, the Council, the European Economic and Social Committee and the Regions. COM(2020) 299 Final. Published on the 08.07.2020.

European Commission (2020b). Powering a climate-neutral economy: An EU Strategy for Energy System Integration. Communication from the Commission to the European Parliament, the Council, the European Economic and Social Committee and the Regions. COM(2020) 299 Final. Published on the 08.07.2020.

Fenwick, M., Kaal, W. A., \& Vermeulen, E. P. (2016). Regulation tomorrow: What happens when technology is faster than the law. American University Business Law Review, 6(3), 561-594.

Galliani, A., \& Pasquadibisceglie, M. S. (2018). A new concept for Italian dispatching market: Decision 300/2017. 2018 110th AEIT International Annual Conference, AEIT 2018, 1-6. https://doi.org/10.23919/AEIT.2018.8577385
Gautier, A. (2020). Merchant Interconnectors in Europe: Merits and Value Drivers. FSR Policy Brief, 2020/05.

Glachant, J.-M. (2019). New business models in the electricity sector. FSR Working Paper RSCAS 2019/44.

ISGAN. (2019). Innovative Regulatory Approaches with Focus on Experimental. Sandboxes Casebooks. ISGAN Annex 2 Smart Grid Case Studies.

Jamasb, T., Llorca, M., Meeus, L., \& Schittekatte, T. (2020). Energy Network Innovation for Green Transition: Economic Issues and Regulatory Options. In Energy Regulation in the Green Transition: an Anthology.

Jamasb, T., \& Pollitt, M. (2007). Incentive regulation of electricity distribution net works : Lessons of experience from Britain. Energy Policy, 35, 6163-6187. https://doi. org/10.1016/i.enpol.2007.06.022

Jenkins, J. D., \& Pérez-Arriaga, I. J. (2017). Improved Regulatory Approaches for the Remuneration of Electricity Distribution Utilities with High Penetrations of Distributed Energy Resources. The Energy Journal, 38(3), 63-92.

Joskow, P. (2019). Competition for Electric Transmission Projects in the U.S.: FERC Order 1000. CEEPR WP 2019-004.

Kessel, C., Meeus, L., \& Schwedler, C. (2011). Experience with Interconnection Merchant Projects under Regulation (EC) 1228/2003: Perspectives for Regulation (EC) 714/2009. Utilities Law Review, 18(4), 147-155.

Lo Schiavo, L., \& Benini, M. (2018). Pilot projects on Battery Energy Storage Systems in the Transmission grid: regulatory framework and first results. 2018 AEIT International Annual Conference. IEEE. https://doi.org/10.23919/AEIT.2018.8577382

Lo Schiavo, L., Bonafede, D., Celaschi, S., \& Colzi, F. (2017). Regulatory Issues in the Development of Electro-Mobility Services : Lessons Learned from the Italian Experience. 1st E-Mobility Power System Integration Symphosium. Berlin. 23 October 2017.

Lo Schiavo, L., Delfanti, M., Fumagalli, E., \& Olivieri, V. (2013). Changing the regulation for regulating the change: Innovation-driven regulatory developments for smart grids , smart metering and e-mobility in Italy. Energy Policy, 57, 506-517. https://doi. org/10.1016/i.enpol.2013.02.022

Marchisio, L., Genoese, F., \& Raffo, F. (2019). Distributed Resources in the Italian Ancillary Services Market: taking stock after two years. Insights - Terna.

Meeus, L., \& Saguan, M. (2011). Innovating grid regulation to regulate grid innovation: From the Orkney Isles to Kriegers Flak via Italy. Renewable Energy, 36(6), 1761-1765.

Meeus, L., \& Schittekatte, T. (2018). New grey areas at the frontiers of European power grids. Electricity Network Regulation in the EU: The Challenges Ahead for Transmission and Distribution, 130-149. https://doi.org/10.4337/9781786436092.00018

Ofgem, 2017. Regulatory Sandbox Window 2 Guidance. The Innovation Link. https:// www.ofgem.gov.uk/system/files/docs/2017/10/regulatory_sandbox_window_2_guidance.pdf (accessed 22 January 2021).

Ofgem, 2018a. Enabling trials through the regulatory sandbox. https://www.ofgem.gov. $\underline{\mathrm{uk} / \mathrm{system} / \mathrm{files} / \mathrm{docs} / 2019 / 02 / \text { enabling_trials_through_the_regulatory_sandbox.pdf }}$ (accessed 22 January 2021)

Ofgem, 2018b. Insights from running the regulatory sandbox. https://www.ofgem.gov.uk/ system/files/docs/2018/10/insights_from_running_the_regulatory_sandbox.pdf_accessed 22 January 2021)

Ofgem, 2018c. Outcome of sandbox window 1. https://www.ofgem.gov.uk/system/files/ docs/2018/09/outcome_of_sandbox_window_1.pdf (accessed 22 January 2021).

Ofgem, 2018d. What is a regulatory sandbox? https://www.ofgem.gov.uk/system/files/ docs/2018/09/what_is_a_regulatory_sandbox.pdf (accessed 22 January 2021).

Ofgem, 2020a. Energy regulation sandbox: Guidance for Innovators. https://www.ofgem.gov. uk/system/files/docs/2020/07/sandbox_guidance_notes.pdf (accessed 22 January 2021).

Ofgem, 2020b. Innovation Link case studies. https://www.ofgem.gov.uk/publications-and-updates/innovation-link-case-studies (accessed 22 January 2021).

Ringe, W.-G., \& Ruof, C. (2020). Regulating Fintech in the EU : the Case for a Guided Sandbox. European Journal of Risk Regulation, 1-26. https://doi.org/10.1017/ err.2020.8

Rious, V., \& Rossetto, N. (2018). The British reference model. In L. Meeus \& J.-M. Glachant (Eds.), Electricity Network Regulation in the EU: The Challenges Ahead for Transmission and Distribution (pp. 3-25). Edward Elgar Publishing. 
RSE (2017). Rapporto di valutazione finale dei progetti dimostrativi per lo sviluppo di infrastrutture di ricarica pubblica per veicoli elettrici.

RVO, 2020a. Experimenten Elektriciteitswet 2015-2018. https://www.rvo.nl/subsidies-regelingen/experimenten-elektriciteitswet (accessed: 18 December 2020).

RVO, 2020b. Experimenten Elektriciteitswet en Gaswet. https://www.rvo.nl/subsidie-en-financieringswijzer/experimenten-elektriciteitswet-en-gaswet (accessed: 18 December 2020).

Schittekatte, T., Pototschnig, A., Meeus, L., Jamasb, T., \& Llorca, M. (2020). Making the TEN-E regulation compatible with the Green Deal : eligibility, selection, and cost allocation for PCIs. FSR Policy Brief 2020/27. https://doi.org/10.2870/304592 van der Waal, E. C., Das, A. M., \& van der Schoor, T. (2020). Participatory experimentation with energy law: Digging in a 'regulatory sandbox' for local energy initiatives in the Netherlands. Energies, 13(2). https://doi.org/10.3390/en13020458

Zetzsche, D. A., Buckley, R. P., Barberis, J. N., \& Arner, D. W. (2017). Regulating a Revolution: From Regulatory Sandboxes to Smart Regulation. Fordham Journal of Corporate and Financial Law, 23(1), 31-104. 